\title{
Article
}

\section{Effect of Gait Imagery Tasks on Lower Limb Muscle Activity With Respect to Body Posture}

Kolarova, B., Krobot, A., Polehlova, K., Hlustik, P. and Richards, Jim Available at https://clok.uclan.ac.uk/14576/

Kolarova, B., Krobot, A., Polehlova, K., Hlustik, P. and Richards, Jim orcid iconORCID: 0000-0002-4004-3115 (2016) Effect of Gait Imagery Tasks on Lower Limb Muscle Activity With Respect to Body Posture. Perceptual and Motor Skills, 122 (2). pp. 411-431. ISSN 0031-5125

It is advisable to refer to the publisher's version if you intend to cite from the work. http://dx.doi.org/10.1177/0031512516640377

For more information about UCLan's research in this area go to http://www.uclan.ac.uk/researchgroups/ and search for <name of research Group>.

For information about Research generally at UCLan please go to http://www.uclan.ac.uk/research/

All outputs in CLoK are protected by Intellectual Property Rights law, including Copyright law. Copyright, IPR and Moral Rights for the works on this site are retained by the individual authors and/or other copyright owners. Terms and conditions for use of this material are defined in the policies page.

\section{CLoK}

Central Lancashire online Knowledge www.clok.uclan.ac.uk

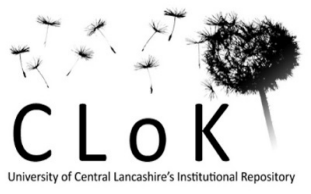


2 ACTIVITY WITH RESPECT TO BODY POSTURE

\section{BARBORA KOLÁŘOVÁ, ALOIS KROBOT, AND KAMILA POLEHLOVÁ}

Department of Physiotherapy, Faculty of Health Sciences, Palacky University Olomouc, Czech Republic

Department of Rehabilitation, University Hospital Olomouc, Czech Republic PETR HLUŠTÍK

Department of Neurology, Faculty of general medicine and dentistry, University Hospital Olomouc, Czech Republic

JIM D. RICHARDS

Allied Health Research Unit, University of Central Lancashire, Preston, United Kingdom

\section{Summary. (max 180 words)-}

The objective of this study was to evaluate the effect of gait imagery tasks on lower limb muscle activity with respect to body posture. The sitting and standing position and lower limb muscle activity was evaluated in 27 healthy female students (24.4 $\pm 1.3 \mathrm{yrs}, 167.2 \pm 5.2 \mathrm{~cm}, 60.10 \pm 6.4 \mathrm{~kg})$. Surface electromyography was assessed during rest and in three different experimental conditions using mental imagery. These included; a rhythmic gait, rhythmic gait simultaneously with observation of a model and rhythmic gait after performing rhythmic gait. The normalized rmsEMG values with respect to corresponding rest position were compared using non-parametric statistics. Standing gait imagery tasks had facilitatory effect on proximal lower limb muscle activity. However, EMG activity of distal leg muscles decreased for all gait imagery tasks in the sitting position, when the proprioceptive feedback was less appropriate. For subsequent gait motor imagery tasks the muscle activity decreased, probably as result of habituation. In conclusion the effect of motor imagery on muscle activity appears to depend on relative strength of facilitatory and inhibitory inputs.

Keywords: gait, motor imagery, surface electromyography 
Motor imagery (MI) represents a pure cognitive process, which positively influences motor performance in healthy subjects which has been shown for sport performance, e.g. gymnastics, ballet and tennis (Guillot, Di Rienzo, Macintyre, Moran, \& Collet, 2012). In addtition this has been shown in patients following motor impairment and has been used in physical therapy during recovery of function (Lotze \& Halsband, 2006; Mizuguchi et al., 2012). Specifically walking skills in neurological patients improved after motor imagery exercise (Dunsky, Dickstein, Marcovitz, Levy, \& Deutsch, 2008; Oostra, Oomen, Vanderstraeten, \& Vingerhoets, 2015). Home-based motor imagery gait training programs have been shown to improve gait parameters including; walking speed, stride length, cadence, single and double support time in chronic post-stroke subjects (Dunsky, Dickstein, Marcovitz, Levy, \& Deutsch, 2008). Motor imagery training includes imagery of walking tasks in combination with physical therapy has been suggested to be more effective for improving gait velocity in sub-acute stroke patients then physical therapy alone (Oostra, Oomen, Vanderstraeten, \& Vingerhoets, 2015). In addition videotape-based locomotor imagery training together with regular physical therapy has been shown to improve walking ability in post-stroke and people with Parkinson's disease more than gait training alone (El-Wishy \& Fayez, 2013; Hwang et al., 2010).

Motor imagery can be described as a conscious mental simulation of an action without actual execution, is accompanied by activity in specific neural substrates (both supraspinal and spinal) similar to those involved in the actual executed movement. Meta-analysis on effect of motor imagery on brain structures conducted by Hetu, et al. (2013) provided evidence that motor imagery activates motor related brain networks including large fronto-parietal and subcortical regions involved in motor execution. Several studies provided evidence that motor imagery increases excitability in corticospinal tracts which projects directly to motoneurons and their interneurons controlling the muscles (Clark, Mahato, Nakazawa, Law, \& Thomas, 2014; Cowley, Clark, \& Ploutz-Snyder, 2008; Oku, Ishida, Okada, \& Hiraoka, 2011; Roosink \& Zijdewind, 2010). This has been shown to increase the excitability of spinal reflexes (Li, Kamper, Stevens, \& Rymer, 2004) and also in muscle proprioceptive structures (muscle spindle Ia afferent fibers) (Bonnet, Decety, Jeannerod, \& Requin, 1997). So it seems that the motoneuron pool of muscle involved in imaginary movement receives summation of neural inputs via descending and ascending neural pathways in similar way as during real movement. The possibility that mental imagery can have an effect on the muscles that create the movement is supported by the positive influence of motor imagery training on muscle strength (Clark et al., 2014; Yue \& Cole, 1992). However the influence of motor imagery on electromyography (EMG) measures is not clear yet. To date several studies have found no significant effect of motor imagery on electromyographic activity during imaginary pointing arm movement for upper limb muscles (Demougeot \& Papaxanthis, 2011; Gentili, Papaxanthis, \& Pozzo, 2006) during imaginary pointing arm movement for upper limb muscles including anterior deltoid, tricpes and biceps brachii, 
pectoralis major. In addition, Ranganathan, Siemionow, Liu, Sahgal, \& Yue (2004) found no increase in activity of biceps brachii and finger abductor during imaginary isometric little finger abduction and elbow flexion, and Lemos, Rodrigues, \& Vargas (2014) who found no increase in activity of the gastrocnemius lateralis during imaginary rising on tiptoes. However, Oku, Ishida, Okada, \& Hiraoka (2011) found increased EMG in extensor carpi radialis activity during imaginary wrist extension and Guillot et al. (2007) and Dickstein, Gazit-Grunwald, Plax, Dunsky, \& Marcovitz (2005) showed increased EMG activity of nine upper limb muscles in agonists, synergists, fixators and antagonists during imaginary lifting a weighted dumbbell and increased EMG activity of gastrocnemius medialis and rectus femoris when performing imaginary rising on tiptoes respectively.

Surface electromyographic measurements reflect, to some extent, the effort of neural system for movement execution as EMG signal is usually proportional to the level of motor unit activity (Richards, 2008). The muscle activity is altered by variations in the balance between inhibitory and facilitatory input which go in parallel to the motoneuron pool, the terminal part of spinal afferent or efferent sensory/motor pathways (Daroff et al., 2012). So it might accepted that even during MI the magnitude of EMG activity reflects the summation of facilitory and inhibitory inputs. This assumption is supported by recent findings, which had shown that the increase of EMG activity during MI mirrors a number of facilitatory inputs including mental effort related to e.g. characteristics of imagined object, the heavier was the object lifted in imagination the showed a greater EMG signal during MI (Bakker, Boschker, \& Chung, 1996) and tends to be more pronounced in complex functional movements (Bakker et al., 1996; Guillot et al., 2012; Guillot et al., 2007). The EMG signal during motor imagery is classified mostly as subliminal (Guillot et al., 2012; Guillot et al., 2007) or background muscle activity (Oku, Ishida, Okada, \& Hiraoka, 2011) which indicates that detectable muscle activity during MI does not have comparable magnitude and phasic pattern to real movement execution. As the amount of increase in EMG amplitude during motor imagery is positively correlated with the amount of corticospinal excitability (Oku, Ishida, Okada, \& Hiraoka, 2011) and with respect to previous findings that corticospinal excitability and brain activity during motor imagery is enhanced with the real sensory feedback generated by holding an object which is imaginary manipulated (Mizuguchi et al., 2012) we speculate that EMG activity during gait imagery may be influenced by character of sensory feedback with respect to sitting (non-default position for walking) or standing (default position for walking) body position during imagination.

With respect to imaginary training protocols in sport or in rehabilitation it has been suggested that simultaneously observing somebody doing the task during motor imagery further positively influences neural activity and enhances motor learning processes (Nedelko, Hassa, Hamzei, Schoenfeld, \& Dettmers, 2012; Roosink \& Zijdewind, 2010; Wright, Williams, \& Holmes, 2014). In similar way with respect to motor learning even previous practice of imaginary movement facilitates 
neural activity more than imagery before practice, improves imagination ability of this movement (Wriessnegger, Steyrl, Koschutnig, \& Muller-Putz, 2014) and combination of imagination with real practice is more effective for motor recovery then movement imagination or execution alone. Therefore the simultaneous observing of imaginary movement will have facilitatory effect on muscle activity.

It has also been previously suggested that the effectivity of the motor imagery training depends on individual's imaging ability (Gregg, Hall, \& Butler, 2010). Subjects with a good motor imagery ability show a greater performance improvement following motor imagery training than do subjects with a poor imagery ability (Mizuguchi, Yamagishi, Nakata, \& Kanosue, 2015).

The aim of the present study was to analyze the effect of gait imagery tasks from the first person perspective on both proximal and distal lower limb muscle activity. Based on the prior finding that motor imagery activates neural structures in similar way as movement execution and that muscle activity reflects the summation of neural inputs coming to motoneuron pool via afferent and efferent pathways we hypothesized that: (1) imagination of gait (which is considered as complex functional task) modulates lower limb muscle activity, (2) the magnitude of muscle activity reflects character of peripheral sensory inflow during imagination with respect to body posture and (3) the magnitude of muscle activity is further influenced with respect to additional cognitive and motor task.

Therefore this study aimed to evaluate the electromyographic activity of proximal and distal lower limb muscles, which participate synergically on gait execution, during gait imagery tasks compare to rest conditions. This would potentially further our understanding of influence of gait imagery task on motor system and the effect of imagining or observing gait activity of lower limb muscles. This in turn provides important information for gait imagery rehabilitation protocols and could increase our understanding of gait control mechanisms.

\section{Method}

\section{Participants}

Twenty seven healthy females participated in this study. Their mean ( \pm SD) age, height and weight were $24.4 \pm 1.3 \mathrm{yrs}, 167.2 \pm 5.2 \mathrm{~cm}$ and $60.10 \pm 6.4 \mathrm{~kg}$. All participants were recruited from students from a Physiotherapy department of Palacky University. All participants had good cognitive function and communicative skills necessary for motor imagery and were able to generate gait motor imagery. Only participants with at least moderate visual and kinesthetic imagery ability, evaluated by Revised Movement Imagery Questionnaire (MIQ-R), were included in the study (Smith \& Collins, 2004). MIQ-R represents a reliable tool to assess motor imagery ability in healthy persons. MIQ-R consists of an eight-item self-report questionnaire using two 7-point scales to evaluate ability to form visual and kinaesthetic mental images (Hall \& Martin, 1997). The exclusion criteria included 
psychiatric, neurological or musculoskeletal disorders, balance or walking problems, the use of a walking aid, chronic pain, pregnancy, the use of medication affecting the level of vigilance and uncorrected visual impairments. The dominant lower limb was the right side in all participants, determined as preference for kicking a ball (Seeley, Umberger, \& Shapiro, 2008). Testing occurred in a quiet room in one day. All participants signed an informed consent prior to participating in this study. The procedures, which were approved by the local ethics committee, were performed according to the ethical standards of the Declaration of Helsinki.

Motor imagery ability measures

When completing the MIQ-R, participants are asked to perform one of four movement tasks and then rate the ease with which they form visual and kinaesthetic images of this movement (from 1 = "very hard to see/feel" to 7 = "very easy to see/feel"). In the study mean MIQ-R scores (SD) were 47.7 (5.9) for both subscales, 24.15 (2.94) for the visual subscale, and 23.15 (3.15) for the kinaesthetic subscale. The MIQ-R has demonstrated adequate internal consistency with Cronbach $\alpha$ coefficients 0.78 and 0.76 for visual and kinaesthetic subscales respectively. MIQ-R mean scores and consistency were comparable to those observed in previous MI studies (Hall \& Martin, 1997; Guillot, et al., 2012). Electromyography measures

Muscle activity was measured using surface EMG using two self-adhesive electrodes (Ag$\mathrm{AgCl})$. The electrodes were placed in parallel to the muscle fibers in the midline over the muscle belly with an inter electrode distance of $2 \mathrm{~cm}$. Prior to placing the EMG surface electrodes, the skin was abraded and cleaned. EMG activity was recorded from biarticular lower limb muscles involved with gait execution by synergistic action (Chvatal \& Ting, 2012). Three distal muscles of the dominant lower limb: tibialis anterior (TA), gastrocnemius lateralis (GL), gastrocnemius medialis (GM), and three proximal muscles of the dominant lower limb: biceps femoris (BF), semitendinosus (ST) and rectus femoris (RF) were measured. The reference electrode was placed over the fibula head. EMG data were recorded at $1000 \mathrm{~Hz}$ using the wireless system TeleMyo 2400T G2 (Noraxon Co., USA) with a system bandwidth was 20-1000 Hz. Real-time EMG signals were sent via telemetry at 1,000 $\mathrm{Hz}$ to an A-D converter (Noraxon Co., USA). The raw EMG signals were full wave rectified and the root mean squared value of EMG (rmsEMG) signals was calculated using a time averaging period of 25 ms (Guillot, et al., 2007). The processing of the signal was performed by using the software MyoResearch XP Master Edition 1.08.17 (Noraxon Co., USA). Raw EMG signal was visually checked prior to processing and analysis to verify the absence of any artifacts.

\section{Procedure}

The test protocol was conducted with respect to previous findings such that the imagination ability was enhanced when imagination was done from first person perspective, and is performed 
with externally given auditive feedback (Guillot, et al., 2007; Heremans, et al., 2012; Koehler, et al., 2012; Mizuguchi, et al., 2012; Roosink \& Zijdewind, 2010).

EMG data were initially collected in two default rest positions, sitting (non-default position for walking) and standing (default position for walking) without performing any voluntary activity or motor imagery, and then within six motor imagery experimental conditions in the following order:

1. gait imagery in the sitting position, gait imagery in the standing position,

2. gait imagery and simultaneous gait observation in the sitting position, gait imagery and simultaneous gait observation in the standing position,

3. gait imagery in the sitting position after gait execution, gait imagery in the standing position after gait execution.

Experimental conditions are illustratively demonstrated in Figure 1.

\section{FIGURE 1}

\section{Figure 1 insert here}

Default sitting or standing positions were standardized for all experimental conditions. In the sitting position, the participants were seated upright in a chair that leaned against the back and arm rest. In the standing position, the participants were standing upright with hands along their body. In both default positions, the feet were placed a pelvic width apart. In all experimental situations, the position of the feet was unchanged.

For every participant and for all tested conditions, the rhythm of gait was given to the participants using a metronome set at 110 beats per minute, to replicate a normal gait cadence All tested participants reported that they were able to imagine gait well at this step frequency. In the first experimental imaginary gait conditions for sitting and standing, the participants were instructed to imagine a rhythmic gait as vividly as possible, in the first person perspective, the instruction was "Imagine yourself walking on the pace of the metronome" without making any actual movements. In second tested conditions, the participants observed the rhythmic gait of a second person in frontal plane from posterior side on the projection screen $(200 \times 200 \mathrm{~cm})$ placed 2 meters in front of them. The participants were instructed to watch the gait and to simultaneously imagine a rhythmic gait as if they were walking (the instruction was "Observe the woman on the screen walking at the pace of the metronome and simultaneously imagine yourself walking at the same pace“). Next, real rhythmic walking at the pace of the metronome in hospital corridor was performed by the participants for a few minutes to enhance further rhythmic gait imagination ability (Wriessnegger, Steyrl, Koschutnig, \& Muller-Putz, 2014). Just after real rhythmic walking, third experimental conditions were performed, the instruction within the gait imagery task after gait execution was the same task as in the first experimental conditions "Imagine yourself walking on the pace of the metronome“. Each gait imagery 
task lasted for approximately 60 seconds. None of participants mentioned feelings of fatigue during the experimental session.

\section{Data processing}

210 The rmsEMG [\%] was calculated for every experimental condition in sitting or standing position and 211 then normalized to the rmsEMG of default sitting or standing rest positions. For the rest sitting and 212 standing positions the average rmsEMG values of all tested the muscles were calculated over a 20 213 seconds interval. These values calculated during the rest condition without any motor imaginary were 214 considered as reference values. For all rhythmic gait imagery tasks the mean rmsEMG values were 215 calculated over six gait cycles for the dominant lower limb. The duration of evaluated EMG period was 6.6 seconds which was calculated from the metronome frequency where one gait cycle was 1.1 seconds. This period was selected from the middle part of the measured data for every experimental condition with respect to adaptation on the imagery task. The mean rmsEMG values during experimental gait imagery tasks were expressed as a percentage of reference value. Gait imaginary experimental tasks conducted in sitting position were normalized to the respective reference value obtained in rest sitting position and gait imaginary tasks conducted in standing position were normalized to the respective reference value obtained in rest standing position for every participant and tested muscle.

\section{Statistical analysis}

Data were tested to determine if they were normally distributed using Kolmogorov-Smirnov test. All data were found not to be normally distributed, $(\mathrm{p}<0.05)$, therefore non-parametric tests were used throughout the analysis. For the statistical analysis the non-parametric Wilcoxon signed-rank test was performed with the alpha value was set at $\mathrm{p}<0.05$. This allowed the comparison of the reference values for sitting and standing positions and normalized EMG data for experimental conditions in sitting and standing positions respectively (hypothesis 1). And the comparison of normalized EMG data with respect to the default sitting and standing positions (hypothesis 2) alpha value was set at $\mathrm{p}<0.05$. The differences between each of the gait imagery conditions in the sitting or standing position (hypothesis 3) were explored with Friedman tests with post-hoc Wilcoxon tests. As normalizaed data for three experimental imagery conditions were compared and the alpha value was calculated using Bonferroni's adjustment as $0.05 / 3$ and set at $\mathrm{p}<0.017$ ). In addition the effect size for 
For all tested muscles in rest default sitting and standing position the EMG activity was almost

242 silent, the mean and standard deviation reference rest electromyography data $[\mu \mathrm{V}]$ are presented in

243 Table 1. All experimental gait imagery conditions were normalized as a percentage of the rest values separately for each posture, muscle and participant, descriptive statistics of these data are presented in Table 2. First gait imagery task in standing position had facilitatory effect on proximal lower limb muscle activity (Table 2, Table 3). However, EMG activity of distal leg muscles decreased for all gait imagery tasks in the sitting position, when the proprioceptive feedback was less appropriate.

TABLE 1

Table 1 insert here

TABLE 2

Table 2 insert here

Gait imagery tasks vs. rest (Hypothesis 1)

Conditions using rhythmic gait imagery mostly indicated an inhibitory effect on lower limb muscle activity compared to the rest default positions (Table 3). In the sitting position this was apparent for GM and GL and for TA in all experimental conditions, for BF and ST during gait imagery and simultaneous gait observation and gait imagery after gait execution.

In the standing position significant inhibition was only present in GL for second gait imagery condition and in TA for second and third gait imagery condition. In the standing position, the first gait imagery task in the proximal tested muscles $(\mathrm{BF}, \mathrm{RF})$ resulted in an increased EMG activity.

TABLE 3

\section{Table 3 insert here}

Standing vs. sitting position (Hypothesis 2)

When comparing of the normalized EMG data between experimental conditions and between the sitting and standing positions, muscle activity was mostly higher in the standing position (Table 3). This support the hypothesis that standing facilitates muscle activity in comparison to sitting. The difference were significant for GL $(\mathrm{p}<0.01, \mathrm{ES}>0.3)$ and $\mathrm{BF}(\mathrm{p}<0.05, \mathrm{ES}>0.3)$ in every experimental 271 (SI3 $\times$ TI3), for ST and RF $(\mathrm{p}<0.05$, ES $>0.3)$ in first gait imagery (SI1 $\times$ TI1) and imagery during gait observation $(\mathrm{SI} 2 \times \mathrm{TI} 2)$ conditions. 
When comparing experimental conditions, in sitting position the EMG activity was lower during the rhythmic gait imagery after rhythmic gait execution in comparison to the second gait imagery condition for $\mathrm{GM}(\mathrm{Z}=2.83, \mathrm{p}=0.005$, $\mathrm{ES}=0.36)$, $\mathrm{GL}(\mathrm{Z}=3.24, \mathrm{p}=0.001, \mathrm{ES}=0.038)$, and TA $(Z=3.73, p<0.001, r=0.49)$ and in comparison to the first gait imagery condition $(\mathrm{SI} 1 \times$ SI3) for GM $(Z=2.64, p=0.01, E S=0.39), G L(Z=2.79, p<0.001, E S=0.44)$, and TA ( $Z=3.63, p<0.001, E S=0.51)$.

In the standing position, the muscle activity was lower in the third tested condition compared to the first tested condition for RF $(Z=3.05, p<0.001$, $E S=0.42)$. For other comparisons the values did not differ significantly.

\section{Discussion}

Guillot (2007) showed that MI was accompanied by subliminal EMG activity of muscles participating on imagined movement execution. However the increase of lower limb muscle activity during rhythmic gait imagery was not major finding in our study. Lower limb muscles mostly decreased EMG activity during the experimental tasks using gait imagery compared to the rest conditions, where EMG activity of all muscles was almost silent (Table 1). This was significant especially for distal leg muscles in the sitting position (Table 2 and Table 3). The muscle activity increase during MI compared to rest conditions was previously demonstrated mostly for upper limb tasks (Bakker, et al., 1996; Guillot, Di Rienzo, et al., 2012; Guillot, et al., 2007; Solodkin, et al., 2004) or for non-gait foot tasks (Bakker, et al., 2007; Bonnet, et al., 1997). To follow on from the results of Bakker et al. (2008) it could be suggested that during gait imagery compared to imagery of non-gait or postural foot task supraspinal control is suppressed to some extent. Bakker et al. (2008) compared corticospinal excitability within motor imagery of simple foot task (dorsiflexion) and MI of gait measured by motor evoked potentials from task-related muscle m. tibialis anterior in sitting position. They found that motor evoked potentials areas increased during motor imagery of simple foot task, however corticospinal excitability within gait imagery increased just in selected group of subjects (5 from 16) who had larger increased during imagined foot dorsiflexion, so compared to the majority of participants this simple task did not show and increase in muscle activity during gait imagery.

As supraspinal control might be suppressed during imagery of postural task we speculate that the less expressed effect of gait imagery on muscle activity could be influenced by neural gait control mechanisms. Rhythmic complex patterns of synergistic muscle activity required for locomotion are to great extent under control of neural autonomy of CPG, neural networks located in lumbosacral spine connected with supraspinal motor regions and with lower limb afferent peripheral sensors (Solopova et al, 2015, Dietz, 2003, 2010; Chvatal \& Ting, 2012; Dietz, 2003; MacKay-Lyons, 2002). 
Motor imagery of lower-limb movements including gait relies mainly on the supplementary motor 310 area, cerebellum, putamen, and parietal regions (Hetu et al., 2013). Activity of these areas is required 311 more for gait planning with respect to changes of external environment rather than for stereotype 312 locomotion which has been shown to be more automatic (Hetu, et al., 2013; la Fougere, et al., 2010). 313 Activity of CPG might be modulated to a great extent by afferent sensory feedback from lower limb 314 receptors even with suppressed supraspinal control than has been previously demonstrated on spinal315 cord-injured humans (Bussel et al, 1996, Dietz, 2003, 2010; Harkema, et al., 1997;) or in situations 316 without any extra demands on gait with respect to e.g. additional task or changes in the external 317 environment (Bussel, et al., 1996; Calancie, et al., 1994). Particularly phasic peripheral sensory 318 information associated with lower limb loading during walking evokes lower limb muscle activity 319 (Harkema et al., 1997). Harkema et al. (1997) found that by 70\% unloaded body weight stepping (but not $100 \%$ unloaded body weight stepping) movements induced by a driven gait orthosis on a treadmill in healthy subjects elicited muscle activity of distal extensor lower limb muscles, namely gastrocnemius medialis and soleus. So the EMG activity of distal lower limb muscles during the gait is to a great extent dependent on phasic peripheral sensory information especially in situations when no extra attention or demands on posture control are needed. The importance of proprioceptive feedback for muscle activity during walking was suggested further McCrea (2001), who found that feedback from extensor proprioceptors induces locomotor dependent reflexes that contribute considerably to extensor muscle activity during real walking. So it is probable that especially distal lower limb motor neurons don’t receive enough facilitatory inputs to evoke muscle activity during stereotype rhythmic gait imagery tasks in sitting position. Furthermore it seems that during the imagining of gait in a position in which walking is impossible dominate inhibitory effect over possible facilitatory on the muscle activity.

The emerging question from these current findings is not only why tested gait imagery conditions do not have facilitatory effect on muscle activity, which was the major focus in previous studies, but why gait imagery tasks resulted in decreased muscle activity compared to the rest condition in our experiment.

To date a decrease of EMG activity during imagination of movement execution task has not been described. Decreased excitability of motor neural system during movement imagery compared to rest condition, specifically decreased activity of corticospinal tract, has been previously reported for imagination of muscle relaxation (Kato, Watanabe, Muraoka, \& Kanosue, 2015) or during imagination of suppressing movements (Sohn, Dang, \& Hallett, 2003) for upper limb tasks. Few studies found decreased corticospinal excitability during imagination of postural tasks in comparison to rest conditions (Hiraoka, 2002; Oishi et al., 1994). Hiraoka (2002) suggested that imagination of stumbling in standing posture lead to decrease excitability of soleus H-reflex and Oishi (1994) found 
that imaginary of skating motion in elite skate sprinters led to suppression of soleus H-reflex during whole period of imaginary movement. All these finding are support the previous suggestion that motor commands during motor imagery must be inhibited throughout the neural system to some extent to prevent overt movement execution (Guillot, 2007; Jeanarod, 2001) as EMG activity (if present) is just at subliminal intensity without tonic specific activity as during real movement (Guillot, 2007; Guillot, 2012; Jeanarod, 2001).

Inhibitory processes, which presumably propagate to the spinal motoneurons in parallel with the excitatory inputs might have origin on the cortical, brainstem or either on spinal level (Jeannerod, 2006; Prut \& Fetz, 1999). We speculate that the cause of EMG decrease, which occurred mostly in sitting position during gait imagery tasks, presumably mostly took place on spinal level as sitting and standing differs mostly by means of different proprioceptive input. It is probable that muscle spindle afferents is gating the strength of Ia afferent synaptic input onto target motor neurons during gait imagery in the same way as during gait execution (MacKay-Lyons, 2002). One of proposed mechanisms of muscle activity inhibition is presynaptic inhibition according to a previous finding that soleus H-reflex excitability as function of EMG level is decreased during gait (Stein \& Capaday, 1998). Presynaptic inhibition reduces the amount of neurotransmitter released at the presynaptic terminal of the Ia axon which lead to decrease in EMG activity (Brooke et al., 1997; Bonnet et al. 1997). Furthermore we speculate that muscle activity decrease during gait imagery task might be influenced by depression of afferent neuronal discharge as has been demonstrated during fictive locomotion in the cat induced by mesencephalic locomotor region stimulation (Perreault et al., 1999). Decrease of muscle and cutaneous afferent-evoked monosynaptic field potentials reflected a reduction of depolarizing synaptic current into spinal neurons during fictive locomotion (Perreault et al., 1999).

\section{The influence of posture}

For all tested muscles in most of experimental conditions was muscle activity during gait imaginary tasks significantly lower in sitting position compared to muscle activity during gait imaginary tasks in standing position (see Table 2, 3). Thus, the standing position compared to sitting position had an excitatory effect on muscle activity during rhythmic gait imagery tasks. Standing posture is congruent with walking and thus offer more appropriate somatosensory (tactile, proprioceptive and visual) feedback compared to incongruent positions with walking such as sitting or lying. Presence of real somatosensory feedback facilitates activity of neural structures within motor imagery and motor observation (Mizuguchi et al., 2012; Vargas et al., 2004). Mizuguchi et al. (2012) found that imagination of squeezing the ball and holding the real ball at the same time enhanced the MEPs in comparison to the same situation just without the ball. Vargas et al. (2004) observed that corticospinal 
excitability increased in situation when hand posture was compatible with the imagined task compared to incompatible hand posture with the imagined task. Saimpont et al., 2012) proved that posture might influence even accuracy of imagined movement, in their experiment the time duration of gait motor imagery in standing posture (body posture congruent with walking) was more comparable with real gait than gait motor imagery in sitting posture. It has been also previously shown, that standing posture compared to supine posture (the one most used throughout the studies concerning effect of gait observation or gait imagery) has excitatory effect on neural structures (Nakazawa et al., 2003; Shimba et al., 2010). Nakazawa et al. (2003) demonstrated that both stretch reflex and MEP elicited in tibialis anterior were significantly greater in standing compare to supine posture (background EMG was silent in both conditions). Shimba et al. (2010) found that even passive standing posture (accomplished by using gait orthosis) had higher impact on increased stretch reflex of $\mathrm{m}$. soleus compared to supine position. This might reflect facilitatory effect of standing position on muscle spindle Ia afferent fibers. Facilitation of muscle spindle activity with respect to position congruent with imaginary movement found also Bonnet et al. (1997). In their study they showed that mental simulation of pressure on a pedal with the foot in reclined sitting position with their feet on two pedals led to larger changes in T-reflex amplitude compared to H-reflex amplitude (activity of muscle spindle Ia afferent fibres is elicited within the T-reflex, but not by H-reflex) in the leg involved in the simulation. Even the extension of the hip in the standing position might have facilitatory effect on muscle activity compared to sitting position, because also afferent input from hip joints is important for the leg muscle activation during locomotion in dependence on hip position (Dietz and Duysens, 2000; Dietz et al., 2002; Grillner \& Rossignol, 1978). Grillner \& Rossignol (1978) previously proved that preventing the hip from extension in chronic spinal cats inhibits the flexors muscle activity. As EMG activity depends on level of motoneuron pool excitation it is probable that muscle proprioceptive (muscle spindle) afferents is gating the strength of Ia afferent synaptic insput onto target motoneurons during gait imagery, same as during gait execution (MacKay-Lyons, 2002). Then the level of proprioreceptors activation might be crucial for the the subtreshold activation of target muscles during gait imagery tasks. This assumption is in accordance with previous studies the appropriate propriceptive feedback (concretly posture congruent with imaginary task) provided excitatory input to the motor system and facilitates muscle activity.

For the proximal tested muscles (BF and RF) the gait imagery task in the standing position was the only experimental condition when the muscle activity increased compared to the rest position. It has been previously suggested that the proximal leg muscles (e.g., BF) are mostly controlled by the monosynaptic corticospinal pathways compared to mostly polysynaptic corticospinal innervations of the distal leg muscles (e.g., GM) (Brouwer \& Ashby, 1991; Cowan, Day, Marsden, \& Rothwell, 1986). So presumably during the gait imagery task, the direct neural input from the cortex to the 
motoneuron may enhance the ability of the cortex to control the proximal leg muscles (Brouwer \& Ashby, 1991). This assumption is in accordance with previous findings that during hand movements dominates monosynaptic cortical-motoneuronal input (Nicolas et al., 2001) and mostly for upper limb movements the presence of EMG activity during imagery tasks has been already demonstrated. It is possible that motor imagery does not provide equivalent neural input to proximal and distal leg muscles, but this has to be further explored. And still just biarticular lower limb muscles were measured. To follow our results it is likely that the imagining of rhythmic gait provides inhibitory input mostly to the distal leg muscles in the default sitting position. In accordance to previously mentioned studies inhibition might reflect the summation of several factors including: decreased supraspinal effort for stereotype gait imagery tasks, spinal inhibitory mechanisms (presynaptic inhibition), different neural drive to the motoneurons of distal and proximal leg muscles, and default sitting posture which does not provide appropriate feedback for real walking. However the results of this study are limited to young woman population with good imagery ability, and to stereotype rhythmic gait imagery task. Therefore, further research is required with respect to different genders and populations.

\section{Comparison of EMG activity during experimental conditions}

Combination of motor imagery and observation (Wright, Williams, \& Holmes, 2014) or previous imagined movement execution (Wriessnegger, Steyrl, Koschutnig, \& Muller-Putz, 2014) enhances activity of neural structures and motor learning processes (Gomes, et al., 2014; Nedelko, Hassa, Hamzei, Schoenfeld, \& Dettmers, 2012) compared to motor imagery itself. Based on this assumption we hypothesized, that both simultaneous motor imagery with motor observation and previous execution of imagined movement would have further facilitatory effect on muscle activity compared to gait imagery alone. So we added these "augmented" imagery conditions in given order to the experimental protocol. However in our experiment the second and the third experimental condition mostly led to muscle activity decrease compared to the first tested situation. As the order of first, second and third experimental conditions were not randomized we suggest that the decrease in muscle activity within repeated tested motor imagery tasks in our experiment might reflect to some extent the gradual habituation effect. It has been previously described, that cortical activity is mostly pronounced during initial trials of complex motor imagery tasks (imagery of volleyball spike attack) compared to second and third motor imagery where the short-term habituation effect might be present (Stecklow et al., 2010). None of tested participants reported feelings of tiredness during the experiment the mental fatigue, which has been previously reported for prolonged imagery tasks (Rozand et al., 2016), was not the reason of decreased muscle activity for subsequent imagery tasks. 
448 We suggest here that more challenging imagery tasks as part of gait rehabilitation are required, then 449 habituation effect might be avoided (Marchal-Crespo et al., 2014).

450

451 The results of this study potentially further our understanding of influence of rhythmic gait 452 imagination on lower limb muscles with respect to the body posture. This in turn provides important 453 information for gait imagery rehabilitation protocols and could increase our understanding of gait 454 control mechanisms. 
Bakker, F. C., Boschker, M. S. J., \& Chung, T. (1996) Changes in muscular activity while imagining weight lifting using stimulus or response propositions. Journal of Sport \& Exercise Psychology, 18(3), 313-324.

Bakker, M., de Lange, F. P., Stevens, J. A., Toni, I., \& Bloem, B. R. (2007) Motor imagery of gait: a quantitative approach. Exp Brain Res, 179(3), 497-504.

Bakker, M., Overeem, S., Snijders, A. H., Borm, G., van Elswijk, G., Toni, I., \& Bloem, B. R. (2008) Motor imagery of foot dorsiflexion and gait: effects on corticospinal excitability. Clin Neurophysiol, 119(11), 2519-2527.

Bonnet, M., Decety, J., Jeannerod, M., \& Requin, J. (1997) Mental simulation of an action modulates the excitability of spinal reflex pathways in man. Brain Res Cogn Brain Res, 5(3), 221-228.

Brouwer, B., \& Ashby, P. (1991) Altered corticospinal projections to lower limb motoneurons in subjects with cerebral palsy. Brain, 114 ( Pt 3), 1395-1407.

Bussel, B., Roby-Brami, A., Neris, O. R., \& Yakovleff, A. (1996) Evidence for a spinal stepping generator in man. Electrophysiological study. Acta Neurobiol Exp (Wars), 56(1), 465-468.

Calancie, B., Needham-Shropshire, B., Jacobs, P., Willer, K., Zych, G., \& Green, B. A. (1994) Involuntary stepping after chronic spinal cord injury. Evidence for a central rhythm generator for locomotion in man. Brain, 117 ( Pt 5), 1143-1159.

Clark, B. C., Mahato, N., Nakazawa, M., Law, T., \& Thomas, J. (2014) The Power of the Mind: The Cortex as a Critical Determinant of Muscle Strength/Weakness. J Neurophysiol, jn 00386 02014.

Cowan, J. M., Day, B. L., Marsden, C., \& Rothwell, J. C. (1986) The effect of percutaneous motor cortex stimulation on $\mathrm{H}$ reflexes in muscles of the arm and leg in intact man. $J$ Physiol, 377, 333-347.

Cowley, P. M., Clark, B. C., \& Ploutz-Snyder, L. L. (2008) Kinesthetic motor imagery and spinal excitability: the effect of contraction intensity and spatial localization. Clin Neurophysiol, 119(8), 1849-1856.

Demougeot, L., \& Papaxanthis, C. (2011) Muscle fatigue affects mental simulation of action. $J$ Neurosci, 31(29), 10712-10720.

Dickstein, R., Gazit-Grunwald, M., Plax, M., Dunsky, A., \& Marcovitz, E. (2005) EMG activity in selected target muscles during imagery rising on tiptoes in healthy adults and poststroke hemiparetic patients. J Mot Behav, 37(6), 475-483.

Dietz, V. (2003) Spinal cord pattern generators for locomotion. Clin Neurophysiol, 114(8), 13791389.

Dietz, V. (2010) Behavior of spinal neurons deprived of supraspinal input. Nat Rev Neurol, 6(3), 167174.

Dunsky, A., Dickstein, R., Marcovitz, E., Levy, S., \& Deutsch, J. E. (2008) Home-based motor imagery training for gait rehabilitation of people with chronic poststroke hemiparesis. Arch Phys Med Rehabil, 89(8), 1580-1588.

El-Wishy, A. A., \& Fayez, E. S. (2013) Effect of Locomotor Imagery Training Added to Physical Therapy Program on Gait Performance in Parkinson Patients: A Randomized Controlled Study. Egyptian Journal of Neurology, Psychiatry \& Neurosurgery, 50(1), 31.

Gentili, R., Papaxanthis, C., \& Pozzo, T. (2006) Improvement and generalization of arm motor performance through motor imagery practice. Neuroscience, 137(3), 761-772.

Gregg, M., Hall, C., \& Butler, A. (2010) The MIQ-RS: A Suitable Option for Examining Movement Imagery Ability. Evid Based Complement Alternat Med, 7(2), 249-257.

Guillot, A., Di Rienzo, F., Macintyre, T., Moran, A., \& Collet, C. (2012) Imagining is Not Doing but Involves Specific Motor Commands: A Review of Experimental Data Related to Motor Inhibition. Front Hum Neurosci, 6, 247. 
Guillot, A., Lebon, F., Rouffet, D., Champely, S., Doyon, J., \& Collet, C. (2007) Muscular responses during motor imagery as a function of muscle contraction types. Int J Psychophysiol, 66(1), 18-27.

Hall, C. R., \& Martin, K. A. (1997) Measuring movement imagery abilities: A revision of the Movement Imagery Questionnaire. . Journal of Mental Imagery, 21(1-2), 143-154.

Harkema, S. J., Hurley, S. L., Patel, U. K., Requejo, P. S., Dobkin, B. H., \& Edgerton, V. R. (1997) Human lumbosacral spinal cord interprets loading during stepping. J Neurophysiol, 77(2), 797-811.

Heremans, E., Nieuwboer, A., Spildooren, J., De Bondt, S., D'Hooge A, M., Helsen, W., \& Feys, P. (2012) Cued motor imagery in patients with multiple sclerosis. Neuroscience, 206, 115-121.

Hetu, S., Gregoire, M., Saimpont, A., Coll, M. P., Eugene, F., Michon, P. E., \& Jackson, P. L. (2013) The neural network of motor imagery: an ALE meta-analysis. Neurosci Biobehav Rev, 37(5), 930-949.

Hiraoka, K. (2002) Imagining stumbling inhibits motor-evoked potentials in the soleus muscle. Int $J$ Neurosci, 112(6), 613-622.

Hwang, S., Jeon, H. S., Yi, C. H., Kwon, O. Y., Cho, S. H., \& You, S. H. (2010) Locomotor imagery training improves gait performance in people with chronic hemiparetic stroke: a controlled clinical trial. Clin Rehabil, 24(6), 514-522.

Chvatal, S. A., \& Ting, L. H. (2012) Voluntary and reactive recruitment of locomotor muscle synergies during perturbed walking. J Neurosci, 32(35), 12237-12250.

Jeannerod, M. (2006) The origin of voluntary action: history of a physiological concept. C R Biol, 329(5-6), 354-362.

Kato, K., Watanabe, J., Muraoka, T., \& Kanosue, K. (2015) Motor imagery of voluntary muscle relaxation induces temporal reduction of corticospinal excitability. Neurosci Res, 92, 39-45.

Koehler, S., Egetemeir, J., Stenneken, P., Koch, S. P., Pauli, P., Fallgatter, A. J., \& Herrmann, M. J. (2012) The human execution/observation matching system investigated with a complex everyday task: a functional near-infrared spectroscopy (fNIRS) study. Neurosci Lett, 508(2), 73-77.

la Fougere, C., Zwergal, A., Rominger, A., Forster, S., Fesl, G., Dieterich, M., . . . Jahn, K. (2010) Real versus imagined locomotion: a [18F]-FDG PET-fMRI comparison. Neuroimage, 50(4), 1589-1598.

Li, S., Kamper, D. G., Stevens, J. A., \& Rymer, W. Z. (2004) The effect of motor imagery on spinal segmental excitability. J Neurosci, 24(43), 9674-9680.

Lotze, M., \& Halsband, U. (2006) Motor imagery. J Physiol Paris, 99(4-6), 386-395.

MacKay-Lyons, M. (2002) Central pattern generation of locomotion: a review of the evidence. Phys Ther, 82(1), 69-83.

McCrea, D. A. (2001) Spinal circuitry of sensorimotor control of locomotion. J Physiol, 533(Pt 1), 41-50.

Mizuguchi, N., Sakamoto, M., Muraoka, T., Moriyama, N., Nakagawa, K., Nakata, H., \& Kanosue, K. (2012) Influence of somatosensory input on corticospinal excitability during motor imagery. Neurosci Lett, 514(1), 127-130.

Mizuguchi, N., Yamagishi, T., Nakata, H., \& Kanosue, K. (2015) The effect of somatosensory input on motor imagery depends upon motor imagery capability. Front Psychol, 6, 104.

Nedelko, V., Hassa, T., Hamzei, F., Schoenfeld, M. A., \& Dettmers, C. (2012) Action imagery combined with action observation activates more corticomotor regions than action observation alone. J Neurol Phys Ther, 36(4), 182-188.

Oku, K., Ishida, H., Okada, Y., \& Hiraoka, K. (2011) Facilitation of corticospinal excitability during motor imagery of wrist movement with visual or quantitative inspection of EMG activity. Percept Mot Skills, 113(3), 982-994.

Oostra, K. M., Oomen, A., Vanderstraeten, G., \& Vingerhoets, G. (2015) Influence of motor imagery training on gait rehabilitation in sub-acute stroke: A randomized controlled trial. $J$ Rehabil Med, 47(3), 204-209. 
Prut, Y., \& Fetz, E. E. (1999) Primate spinal interneurons show pre-movement instructed delay activity. Nature, 401(6753), 590-594.

Ranganathan, V. K., Siemionow, V., Liu, J. Z., Sahgal, V., \& Yue, G. H. (2004) From mental power to muscle power--gaining strength by using the mind. Neuropsychologia, 42(7), 944-956.

Roosink, M., \& Zijdewind, I. (2010) Corticospinal excitability during observation and imagery of simple and complex hand tasks: implications for motor rehabilitation. Behav Brain Res, 213(1), 35-41.

Seeley, M. K., Umberger, B. R., \& Shapiro, R. (2008) A test of the functional asymmetry hypothesis in walking. Gait Posture, 28(1), 24-28.

Smith, D., \& Collins, D. (2004) Mental practice, motor performance, and the late CNV. Journal of Sport \& Exercise Psychology, 26(3), 412-426.

Sohn, Y. H., Dang, N., \& Hallett, M. (2003) Suppression of corticospinal excitability during negative motor imagery. $J$ Neurophysiol, 90(4), 2303-2309.

Solodkin, A., Hlustik, P., Chen, E. E., \& Small, S. L. (2004) Fine modulation in network activation during motor execution and motor imagery. Cereb Cortex, 14(11), 1246-1255.

Van de Crommert, H. W., Mulder, T., \& Duysens, J. (1998) Neural control of locomotion: sensory control of the central pattern generator and its relation to treadmill training. Gait Posture, 7(3), 251-263.

Wriessnegger, S. C., Steyrl, D., Koschutnig, K., \& Muller-Putz, G. R. (2014) Short time sports exercise boosts motor imagery patterns: implications of mental practice in rehabilitation programs. Front Hum Neurosci, 8, 469.

Wright, D. J., Williams, J., \& Holmes, P. S. (2014) Combined action observation and imagery facilitates corticospinal excitability. Front Hum Neurosci, 8, 951.

Yue, G., \& Cole, K. J. (1992) Strength increases from the motor program: comparison of training with maximal voluntary and imagined muscle contractions. J Neurophysiol, 67(5), 11141123. 
Aoki, H., Tsukahara, R., \& Yabe, K. (2002) Cortical and spinal motor excitability during the premovement EMG silent period prior to rapid voluntary movement in humans. Brain research, 949, 178-187.

Bakker, F. C., Boschker, M. S. J., \& Chung, T. (1996) Changes in muscular activity while imagining 588 weight lifting using stimulus or response propositions. Journal of sport \& exercise psychology, 18, 313-324.

Bakker, M., de Lange, F. P., Stevens, J. A., Toni, I., \& Bloem, B. R. (2007) Motor imagery of gait: a quantitative approach. Experimental brain research. Experimentelle Hirnforschung. Experimentation cerebrale, 179, 497-504.

Beattie, K., Kenny, I. C., Lyons, M., \& Carson, B. P. (2014) The effect of strength training on performance in endurance athletes. Sports medicine, 44, 845-865.

Bonnet, M., Decety, J., Jeannerod, M., \& Requin, J. (1997) Mental simulation of an action modulates the excitability of spinal reflex pathways in man. Brain research. Cognitive brain research,5, 221-228.

Brouwer, B., \& Ashby, P. (1991) Altered corticospinal projections to lower limb motoneurons in subjects with cerebral palsy. Brain : a journal of neurology, 114 , 1395-1407.

Bussel, B., Roby-Brami, A., Neris, O. R., \& Yakovleff, A. (1996) Evidence for a spinal stepping generator in man. Electrophysiological study. Acta neurobiologiae experimentalis, 56, 465468.

Calancie, B., Needham-Shropshire, B., Jacobs, P., Willer, K., Zych, G., \& Green, B. A. (1994) Involuntary stepping after chronic spinal cord injury. Evidence for a central rhythm generator for locomotion in man. Brain : a journal of neurology, 117, 1143-1159.

Clark, B. C., Mahato, N., Nakazawa, M., Law, T., \& Thomas, J. (2014) The Power of the Mind: The Cortex as a Critical Determinant of Muscle Strength/Weakness. Journal of neurophysiology, 112, 3219-3226.

Cowan, J. M., Day, B. L., Marsden, C., \& Rothwell, J. C. (1986) The effect of percutaneous motor cortex stimulation on $\mathrm{H}$ reflexes in muscles of the arm and leg in intact man. The Journal of physiology, 377, 333-347.

Decety, J. (1996) The neurophysiological basis of motor imagery. Behavioural brain research, 77, 45-52.

Dietz, V. (2003) Spinal cord pattern generators for locomotion. Clinical neurophysiology : official journal of the International Federation of Clinical Neurophysiology, 114(8), 1379-1389.

Dietz, V. (2010) Behavior of spinal neurons deprived of supraspinal input. Nature reviews. Neurology, 6, 167-174. 
Dietz, V., \& Duysens, J. (2000) Significance of load receptor input during locomotion: a review. Gait \& posture, $11,102-110$.

Dunsky, A., Dickstein, R., Marcovitz, E., Levy, S., \& Deutsch, J. E. (2008) Home-based motor imagery training for gait rehabilitation of people with chronic poststroke hemiparesis. Archives of physical medicine and rehabilitation, 89, 1580-1588.

Fadiga, L., Buccino, G., Craighero, L., Fogassi, L., Gallese, V., \& Pavesi, G. (1999) Corticospinal excitability is specifically modulated by motor imagery: a magnetic stimulation study. Neuropsychologia, 37, 147-158.

Grillner, S., \& Rossignol, S. (1978) On the initiation of the swing phase of locomotion in chronic spinal cats. Brain research, 146, 269-277.

Fritz, C. O., Morris, P.E., Richler, J. J. (2012) Effect size estimates: current use, calculations, and interpretation. Journal of experimental psychology General, 141, 2-18.

Gomes, T. V., Ugrinowitsch H., Marinho, N., Shea, J. B., Raisbeck, L. D., Benda, R. N. (2014) Effects of mental practice in novice learners in a serial positioning skill acquisition. Perceptual and motor skills, 119, 397-414.

Guillot, A., Desliens, S., Rouyer, C., \& Rogowski, I. (2013) Motor imagery and tennis serve performance: the external focus efficacy. Journal of sports science \& medicine 12, 332-338.

Guillot, A., Di Rienzo, F., Macintyre, T., Moran, A., \& Collet, C. (2012) Imagining is Not Doing but Involves Specific Motor Commands: A Review of Experimental Data Related to Motor Inhibition. Frontiers in human neuroscience, 6, 247.

Guillot, A., Genevois, C., Desliens, S., Saieb, S., \& Rogowski, I. (2012) Motor imagery and 'placeboracket effects' in tennis serve performance. Psychol Sport Exerc, 13, 533-540.

Guillot, A., Lebon, F., Rouffet, D., Champely, S., Doyon, J., \& Collet, C. (2007) Muscular responses during motor imagery as a function of muscle contraction types. International journal of psychophysiology : official journal of the International Organization of Psychophysiology, 66, 18-27.

Hall, C. R, \& Martin, K. A. (1997) Measuring movement imagery abilities: a revision of the Movement Imagery Questionnaire. Journal of Mental Imagery, 21, 143-154.

Harkema, S. J., Hurley, S. L., Patel, U. K., Requejo, P. S., Dobkin, B. H., \& Edgerton, V. R. (1997) Human lumbosacral spinal cord interprets loading during stepping. Journal of neurophysiology, 77, 797-811.

Heremans, E., Nieuwboer, A., Spildooren, J., De Bondt, S., D'Hooge A, M., Helsen, W., \& Feys, P. (2012) Cued motor imagery in patients with multiple sclerosis. Neuroscience, 206, 115-121. 
Hetu, S., Gregoire, M., Saimpont, A., Coll, M. P., Eugene, F., Michon, P. E., \& Jackson, P. L. (2013) The neural network of motor imagery: an ALE meta-analysis. Neuroscience and biobehavioral reviews, 37, 930-949.

Jeannerod, M. (2006) Motor cognition: What actions tell the Self. New York: Oxford University Press.

Jeannerod, M. (2001) Neural simulation of action: a unifying mechanism for motor cognition. NeuroImage, 14, S103-109.

Jeon, H., Kim, J., Ali, A., \& Choi, S. (2014) Noise distraction and mental practice in closed and open motor skills. Perceptual and motor skills, 119, 156-168.

Kolarova, B., Krobot, A., Habermannova, P., Kolar, P., \& Bastlova P. (2015). Motor imagery and motor observation in cognitive rehabilitation. Rehabilitacia, 52, in-press.

Kaufman, M. T., Churchland, M. M., Ryu, S. I., \& Shenoy, K. V. (2014) Cortical activity in the null space: permitting preparation without movement. Nature neuroscience, 17, 440-448.

Kho, A. Y., Liu, K. P., \& Chung, R. C. (2014) Meta-analysis on the effect of mental imagery on motor recovery of the hemiplegic upper extremity function. Australian occupational therapy journal, 61, 38-48.

Koehler, S., Egetemeir, J., Stenneken, P., Koch, S. P., Pauli, P., Fallgatter, A. J., \& Herrmann, M. J. (2012) The human execution/observation matching system investigated with a complex everyday task: a functional near-infrared spectroscopy (fNIRS) study. Neuroscience letters, 508, 73-77.

la Fougere, C., Zwergal, A., Rominger, A., Forster, S., Fesl, G., Dieterich, M., . . Jahn, K. (2010) Real versus imagined locomotion: a [18F]-FDG PET-fMRI comparison. NeuroImage, 50, 1589-1598.

Lemos, T., Rodrigues, E. C., \& Vargas, C. D. (2014) Motor imagery modulation of postural sway is accompanied by changes in the EMG-COP association. Neuroscience letters, 577, 101-105.

Lotze, M. (2013) Kinesthetic imagery of musical performance. Frontiers in human neuroscience, 7 , 280.

MacKay-Lyons, M. (2002) Central pattern generation of locomotion: a review of the evidence. Physical therapy, 82, 69-83.

Mizuguchi, N., Nakata, H., Hayashi, T., Sakamoto, M., Muraoka, T., Uchida, Y., \& Kanosue, K. (2013) Brain activity during motor imagery of an action with an object: a functional magnetic resonance imaging study. Neuroscience research, 76, 150-155.

Mizuguchi, N., Sakamoto, M., Muraoka, T., Moriyama, N., Nakagawa, K., Nakata, H., \& Kanosue, K. (2012) Influence of somatosensory input on corticospinal excitability during motor imagery. Neuroscience letters, 514, 127-130. 
686

687

688

689

690

691

692

693

694

695

696

697

698

699

700

701

702

703

704

705

706

707

708

709

710

711

712

713

714

715

716

717

718

Mulder, T. (2007) Motor imagery and action observation: cognitive tools for rehabilitation. Journal of neural transmission, 114, 1265-1278.

Nakazawa, K., Kawashima, N., Obata, H., Yamanaka, K., Nozaki, D., \& Akai, M. (2003) Facilitation of both stretch reflex and corticospinal pathways of the tibialis anterior muscle during standing in humans. Neuroscience letters, 338, 53-56.

Nedelko, V., Hassa, T., Hamzei, F., Schoenfeld, M. A., Dettmers, C. (2012) Action imagery combined with action observation activates more corticomotor regions than action observation alone. J Neurol Phys Ther 36, 182-188.

Oku, K., Ishida, H., Okada, Y., \& Hiraoka, K. (2011) Facilitation of corticospinal excitability during motor imagery of wrist movement with visual or quantitative inspection of EMG activity. Perceptual and motor skills, 113, 982-994.

Prut, Y., \& Fetz, E. E. (1999) Primate spinal interneurons show pre-movement instructed delay activity. Nature, 401,, 590-594.

Richards, J. (2008) Biomechanics in clinic and research. Churchill Livingstone, London. ISBN 9780-443-10170-0.

Roosink, M., \& Zijdewind, I. (2010) Corticospinal excitability during observation and imagery of simple and complex hand tasks: implications for motor rehabilitation. Behavioural brain research, 213,, 35-41.

Roy, F. D., \& Gorassini, M. A. (2008) Peripheral sensory activation of cortical circuits in the leg motor cortex of man. The Journal of physiology, 586, 4091-4105.

Seeley, M. K., Umberger, B. R., \& Shapiro, R. (2008) A test of the functional asymmetry hypothesis in walking. Gait \& posture, 28, 24-28.

Shimba, S., Kawashima, N., Ohta, Y., Yamamoto, S., \& Nakazawa, K. (2010) Enhanced stretch reflex excitability in the soleus muscle during passive standing posture in humans. Journal of electromyography and kinesiology : official journal of the International Society of Electrophysiological Kinesiology, 20 , 406-412.

Smith, D., \& Collins, D. (2004) Mental practice, motor performance, and the late CNV. Journal of sport \& exercise psychology, 26, 412-426.

Solodkin, A., Hlustik, P., Chen, E. E., \& Small, S. L. (2004) Fine modulation in network activation during motor execution and motor imagery. Cerebral cortex, 14, 1246-1255.

Tsukahara, R., Aoki, H., Yabe, K., \& Mano, T. (1995) Effects of premotion silent period on single motor unit firing at initiation of a rapid contraction. Electroencephalography and clinical neurophysiology, 97, 223-230. 
Van de Crommert, H. W., Mulder, T., \& Duysens, J. (1998) Neural control of locomotion: sensory control of the central pattern generator and its relation to treadmill training. Gait \& posture, 7, 251-263.

Wriessnegger, S. C., Steyrl, D., Koschutnig, K., Müller-Putz, G. R. (2014) Short time sports exercise boosts motor imagery patterns: implications of mental practice in rehabilitation programs. Frontiers in human neuroscience, 30, 469.

Wright, D. J., Williams, J., Holmes, P. S. (2014) Combined action observation and imagery facilitates corticospinal excitability. Frontiers in human neuroscience, 8, 951.

Yue, G., \& Cole, K. J. (1992) Strength increases from the motor program: comparison of training with maximal voluntary and imagined muscle contractions. Journal of neurophysiology, 67, 1114-1123.

Abeer A. El-Wishy, Eman S. Fayez Effect of Locomotor I magery Training Added to Physical Therapy Program on Gait Performance in Parkinson Patients: A Randomized Controlled Study

(Chvatal \& Ting, 2012 - Voluntary and Reactive Recruitment of Locomotor Muscle Synergies during Perturbed Walking)

Spinal circuitry of sensorimotor control of locomotion

David A McCrea Depression of muscle and cutaneous afferent-evoked monosynaptic field potentials during fictive locomotion in the cat M-C Perreault, S J Shefchyk, I Jimenez, D A McCrea J Physiol. 1999 December 15; 521(Pt 3): 691-703. doi: 10.1111/j.1469-7793.1999.00691.x

Marcus Vinicius Stecklow; Antonio Fernando Catelli Infantosi ${ }^{\mathrm{I}}$; Maurício Cagy ${ }^{\mathrm{II}}$ EEG changes during sequences of visual and kinesthetic motor imagery Arquivos de Neuro-Psiquiatria, ISSN 0004-282X, Arq. Neuro-Psiquiatr. vol.68 no.4 São Paulo Aug. 2010

http://dx.doi.org/10.1590/S0004-282X2010000400015

Hiraoka, 2012. Imagining stumbling inhibits motor-evoked potentials in the soleus muscle" Daroff, 2012,Bradley's Neurology in Clinical Practice 
Rozand V, Lebon F, Stapley PJ, Papaxanthis C, Lepers R (2016). A prolonged motor imagery session alter imagined and actual movement durations: Potential implications for neurorehabilitation.Behav Brain Res. 2016 Jan 15;297:67-75. doi: 10.1016/j.bbr.2015.09.036. Epub 2015 Sep 30.

. J Neurosci. 2011 Jul 20;31(29):10712-20. doi: 10.1523/JNEUROSCI.6032-10.2011.

\section{Muscle fatigue affects mental simulation of action.}

Demougeot $\mathrm{L}^{1}$, Papaxanthis C.

Neuropsychologia. 2004;42(7):944-56.

\section{From mental power to muscle power--gaining strength by using the mind.}

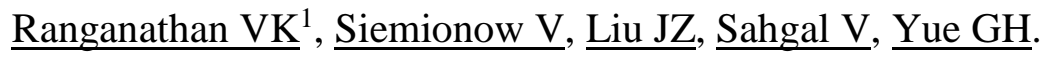

- G. Nicolas, et al.Corticospinal excitation of presumed cervical propriospinal neurones and its reversal to inhibition in humans J. Physiol. (Lond.), 533 (2001), pp. 903-919 
FIGURE 1

764 Illustration of tested experimental conditions

\section{Gait imagery conditions Gait imagery and observation conditions}
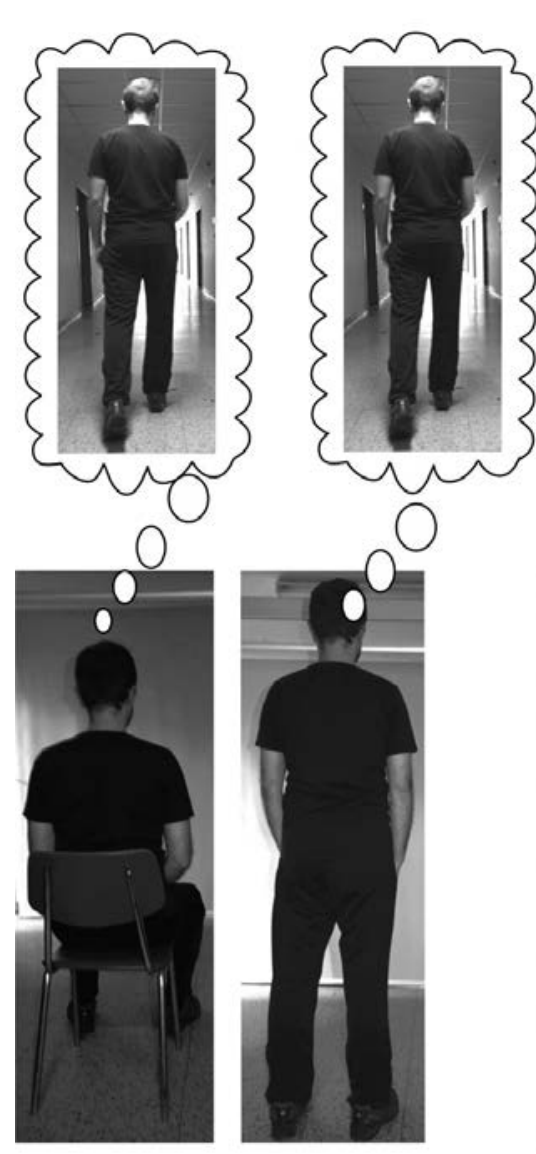

765

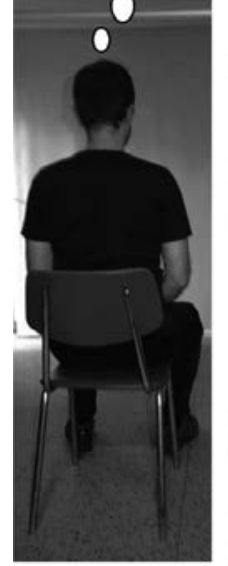

SI1/ SI3 TI1/ TI3

766

\section{TABLE 1}

768 Mean EMG $[\mu \mathrm{V}]$ reference values $( \pm \mathrm{SD})$ for all tested muscles in default sitting and standing positions

\begin{tabular}{|c|c|c|c|c|c|c|c|c|c|c|c|c|}
\hline & \multicolumn{2}{|c|}{$\begin{array}{l}\text { Gastrocnemius } \\
\text { medialis }\end{array}$} & \multicolumn{2}{|c|}{$\begin{array}{l}\text { Gastrocnemius } \\
\text { lateralis }\end{array}$} & \multicolumn{2}{|c|}{$\begin{array}{l}\text { Tibialis } \\
\text { anterior }\end{array}$} & \multicolumn{2}{|c|}{ Biceps femoris } & \multicolumn{2}{|c|}{ Semitendinosus } & \multicolumn{2}{|c|}{ Rectus femoris } \\
\hline & $M$ & $S D$ & $M$ & $S D$ & $M$ & $S D$ & $M$ & $S D$ & $M$ & $S D$ & $M$ & $S D$ \\
\hline $\begin{array}{l}\text { Sitting } \\
\text { position }\end{array}$ & 1.35 & 0.53 & 1.48 & 0.52 & 1.59 & 0.53 & 1.3 & 0.39 & 1.2 & 0.4 & 1.21 & 0.48 \\
\hline $\begin{array}{l}\text { Standing } \\
\text { position }\end{array}$ & 6.17 & 3.72 & 3.65 & 1.79 & 2.45 & 0.96 & 2.6 & 2.57 & 2.82 & 3.6 & 1.72 & 1.4 \\
\hline
\end{tabular}


TABLE 2

772 Normalized elekctromyographic activity with respect to reference value for every muscle [\%] during 773 gait imagery tasks in sitting and standing position

\begin{tabular}{|c|c|c|c|c|c|c|c|}
\hline & & \multicolumn{2}{|c|}{ Gait imagery } & \multicolumn{2}{|c|}{ Gait imagery and observation } & \multicolumn{2}{|c|}{$\begin{array}{lll}\text { Gait imagery after } & \text { gait } \\
\text { execution } & & \end{array}$} \\
\hline & & Med & $I Q R(Q 1-Q 3)$ & Med & $I Q R(Q 1-Q 3)$ & Med & $I Q R(Q 1-Q 3)$ \\
\hline \multirow{2}{*}{$\begin{array}{l}\text { Gastrocnemius } \\
\text { lateralis }\end{array}$} & $\mathrm{S}$ & 73.15 & $(58.31-97.48)$ & 69.07 & $(54.05-92.82)$ & 61.62 & $(45.73-84.55)$ \\
\hline & $\mathrm{T}$ & 95.33 & $(85.23-127.63)$ & 87.31 & (70.27-95.68) & 89.85 & $(81.15-106.95)$ \\
\hline \multirow{2}{*}{$\begin{array}{l}\text { Gastrocnemius } \\
\text { medialis }\end{array}$} & S & 80.64 & $(54.15-97.92)$ & 79.13 & $(51.56-98.24)$ & 60.22 & $(45.91-91.24)$ \\
\hline & $\mathrm{T}$ & 97.19 & $(78.13-129.47)$ & 84.53 & $(70.58-109.11)$ & 91.09 & $(75.83-122.77)$ \\
\hline \multirow[t]{2}{*}{ Tibialis anterior } & S & 75.24 & $(64.25-112.14)$ & 77.7 & $(62.84-95)$ & 59.53 & $(50.49-86.9)$ \\
\hline & $\mathrm{T}$ & 96.58 & $(75.73-119.36)$ & 88.13 & $(82.11-99.03)$ & 85.34 & $(70.78-103.78)$ \\
\hline \multirow[t]{2}{*}{ Biceps femoris } & S & 117.9 & $(91.09-221.63)$ & 101.49 & $(86.37-151.14)$ & 104.77 & $(82.31-129.04)$ \\
\hline & $\mathrm{T}$ & 93.5 & $(88.57-103.43)$ & 91.48 & $(82.49-102.03)$ & 85.86 & (78.97-98.64) \\
\hline \multirow[t]{2}{*}{ Semitendinosus } & $\mathrm{S}$ & 92.26 & $(78.35-108.78)$ & 88.40 & (76.73-102.7) & 87.33 & $(76.62-107.02)$ \\
\hline & $\mathrm{T}$ & 111.28 & $(89.03-158.43)$ & 99.1 & $(87.29-129.14)$ & 98.15 & $(71.07-148.37)$ \\
\hline \multirow[t]{2}{*}{ Rectus femoris } & $\mathrm{S}$ & 91.32 & $(86.17-106.95)$ & 90.33 & $(82.06-100.34)$ & 90.83 & $(75.08-104.5)$ \\
\hline & $\mathrm{T}$ & 111.11 & $(93.8-270.79)$ & 98.3 & (84.09-156.77) & 97.24 & (78.19-154.44) \\
\hline
\end{tabular}

$\mathrm{S}-$ sitting position, $\mathrm{T}-$ standing position, Med - median, $(\mathrm{Q} 1-\mathrm{Q} 3)-\left(25^{\text {th }}-75^{\text {th }}\right.$ percentile of data $)$ 
TABLE 3

783 Results of statistical analysis (Wilcoxon signed rank test and Effect Size) of changes in the muscle 784 activity during gait imagery tasks

\begin{tabular}{|c|c|c|c|c|c|c|c|c|c|c|}
\hline & & \multicolumn{3}{|c|}{$\begin{array}{l}\text { gait imagery tasks in the } \\
\text { sitting position compare to } \\
\text { default sitting rest position }\end{array}$} & \multicolumn{3}{|c|}{$\begin{array}{l}\text { gait imagery tasks in the } \\
\text { standing position compare to } \\
\text { default standing rest position }\end{array}$} & \multicolumn{3}{|c|}{$\begin{array}{l}\text { gait imagery tasks in the } \\
\text { sitting position compare to } \\
\text { gait imagery tasks in the } \\
\text { standing position }\end{array}$} \\
\hline & & Wilcoxon's & & Effect & Wilcoxon's & & Effect & Wilcoxon's & & Effect \\
\hline & & $Z$ & $p$ & Size & $Z$ & $p$ & Size & $Z$ & $p$ & Size \\
\hline \multirow{3}{*}{$\begin{array}{l}\text { Gastrocnemius } \\
\text { medialis }\end{array}$} & $\mathrm{I} 1$ & 3.00 & $<.001$ & 0.41 & 0.29 & 0.77 & 0.04 & 2.21 & 0.03 & 0.3 \\
\hline & I2 & 3.15 & $<.001$ & 0.43 & 1.78 & 0.08 & 0.24 & 1.42 & 0.16 & 0.19 \\
\hline & I3 & 4.08 & $<.001$ & 0.56 & 0.29 & 0.77 & 0.04 & 3.99 & $<.001$ & 0.54 \\
\hline \multirow{3}{*}{$\begin{array}{l}\text { Gastrocnemeius } \\
\text { lateralis }\end{array}$} & I1 & 3.29 & $<.001$ & 0.45 & 0.65 & 0.52 & -0.08 & 4.30 & $<.001$ & 0.58 \\
\hline & $\mathrm{I} 2$ & 4.04 & $<.001$ & 0.55 & 2.71 & 0.01 & 0.34 & 2.79 & 0.01 & 0.38 \\
\hline & I3 & 4.42 & $<.001$ & 0.6 & 1.15 & 0.25 & 0.16 & 4.18 & $<.001$ & 0.59 \\
\hline \multirow[t]{3}{*}{ Tibialis anterior } & I1 & 2.16 & 0.03 & 0.29 & 0.36 & 0.72 & 0.05 & 2.38 & 0.02 & 0.32 \\
\hline & $\mathrm{I} 2$ & 2.26 & 0.02 & 0.31 & 2.07 & 0.04 & 0.28 & 1.39 & 0.16 & 0.19 \\
\hline & I3 & 3.89 & $<.001$ & 0.53 & 2.81 & $<.001$ & 0.38 & 3.08 & $<.001$ & 0.42 \\
\hline \multirow[t]{3}{*}{ Biceps Femoris } & I1 & 1.71 & 0.09 & 0.23 & 2.16 & 0.03 & -0.29 & 2.59 & 0.01 & 0.35 \\
\hline & I2 & 3.05 & $<.001$ & 0.42 & 1.13 & 0.26 & -0.15 & 2.64 & 0.01 & 0.36 \\
\hline & I3 & 3.10 & $<.001$ & 0.42 & 0.77 & 0.44 & -0.11 & 1.99 & 0.05 & 0.271 \\
\hline \multirow[t]{3}{*}{ Semitendinosus } & I1 & 1.42 & 0.16 & 0.19 & 1.75 & 0.08 & 0.24 & 2.50 & 0.01 & 0.34 \\
\hline & I2 & 3.17 & $<.001$ & 0.43 & 0.53 & 0.60 & -0.07 & 1.80 & 0.07 & 0.26 \\
\hline & I3 & 2.09 & 0.04 & 0.28 & 0,22 & 0,83 & -0.03 & 1,13 & 0.26 & 0.15 \\
\hline \multirow[t]{3}{*}{ Rectus femoris } & $\mathrm{I} 1$ & 1.18 & 0.24 & 0.16 & 2.45 & 0.01 & -0.33 & 3.39 & $<.001$ & 0.46 \\
\hline & I2 & 1.95 & 0.05 & 0.27 & 0.86 & 0.39 & -0.12 & 2.35 & 0.02 & 0.32 \\
\hline & I3 & 1.49 & 0.14 & 0.2 & 0.26 & 0.79 & -0.04 & 0.96 & 0.34 & 0.13 \\
\hline
\end{tabular}


